\title{
EVIDENCE THAT THE DEGREE OF OBSTRUCTIVE SLEEP APNEA MAY NOT INCREASE MYOCARDIAL ISCHEMIA AND ARRHYTHMIAS IN PATIENTS WITH STABLE CORONARY ARTERY DISEASE
}

\author{
Cristiana Marques de Araújo, ${ }^{I}$ Maria Cecilia Solimene, Cesar Jose Grupi, ${ }^{I}$

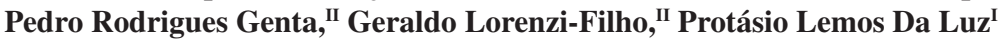

doi: 10.1590/S1807-59322009000300013

Araújo CM, Solimene MC, Grupi CJ, Genta PR, Lorenzi-Filho G Da Luz PL. Evidence that the degree of obstructive sleep apnea may not increase myocardial ischemia and arrhythmias in patients with stable coronary artery disease. Clinics. 2009;64(3):223-30.

ABSTRACT: There is controversy regarding whether obstructive sleep apnea is responsible for triggering myocardial ischemia, arrhythmias and heart rate variability in patients with coronary artery disease.

OBJETIVE: The objective of this study was to identify relationships between sleep apnea, myocardial ischemia and cardiac arrhythmia in patients with coronary artery disease.

METHODS: Fifty-three patients with stable coronary disease underwent simultaneous polysomnography and electrocardiographic Holter recording. The apnea-hypopnea index (AHI) was defined as the number of apneas/hypopneas per hour of sleep. Patients were divided into a Control group (AHI15, $\mathrm{n}=23 \mathrm{pts}$ ) and an Apnea group (AHI $>15, \mathrm{n}=30 \mathrm{pts}$ ). A subgroup of 13 patients with an AHI $>30$ (Severe Apnea group) was also studied. We analyzed ischemic episodes (ST-segment depressions $>1 \mathrm{~mm}, \geq 1 \mathrm{~min}$ ), heart rate variability and the occurrence of arrhythmias during wakefulness and sleep.

RESULTS: Baseline clinical characteristics among the groups were similar except for higher blood pressure in the Apnea groups $(\mathrm{p}<0.05)$. Myocardial ischemia was recorded in $39(73.6 \%)$ patients. The number and duration of ischemic episodes significantly decreased during sleep in all groups; during wakefulness, patients with severe apnea exhibited fewer and shorter episodes in comparison with the controls. There were no significant differences in heart rate variability or in the occurrence of arrhythmias among the groups. Malignant ventricular arrhythmias, atrial fibrillation/flutter, bradycardia and high-degree atrioventricular blocks were not detected.

CONCLUSION: Obstructive sleep apnea was not related to myocardial ischemia, heart rate variability or arrhythmias in patients with stable coronary artery disease and did not alter the circadian pattern of myocardial ischemia.

KEYWORDS: Sleep apnea; Myocardial ischemia; Heart rate variability; Arrhythmias.

\section{INTRODUCTION}

Sleep apnea is reported in about $2 \%$ of middle-aged

\footnotetext{
'Departament of Clinical Cardiology, Instituto do Coração (InCor) do Hospital das Clínicas, Faculdade de Medicina, Universidade de São Paulo - São Paulo/SP, Brazil

"Division of Pulmonology and Sleep Laboratory, Instituto do Coração (InCor) do Hospital das Clinicas, Faculdade de Medicina, Universidade de São Paulo, São Paulo/SP, Brasil.

Tel.: 55113069.5447

Email: daluzp@incor.usp.br

Received for publication on October 29, 2008

Accepted for publication on December 08, 2008
}

women and $4 \%$ of middle-aged men, but prevalence rates of up to $24 \%$ of the adult population have been observed. ${ }^{1}$ Most of the patients are elderly, male and obese with increased neck circumference and craniofacial abnormalities. A higher prevalence is also observed in diabetics, and among those who drink, or who use sedatives and hypnotics. Sleep apnea can be classified as obstructive, central or mixed. The obstructive type (OSA) is the most frequent and is associated with high morbidity; it is characterized by recurrent episodes of partial or complete obstruction of the upper airways during sleep, with a consequent decrease in oxygen saturation. ${ }^{2,3}$ The severity of apnea is defined by the 
apnea-hypopnea index (AHI) as mild (AHI between 5 and 15), moderate (AHI between 16 and 30) and severe (AHI > 30), with hemodynamic changes in individuals with an AHI $>15 .^{2}$ An increased incidence of OSA has been reported among patients with cardiovascular diseases, ${ }^{4,5}$ and there is evidence that cardiovascular risk may decrease in these patients when OSA is treated efficiently. ${ }^{6}$

Frequent episodes of hypoxemia in the context of apnea have been associated with increased sympathetic activity, endothelial dysfunction ${ }^{8}$ and systemic inflammation, ${ }^{9}$ all of which are implicated in the process of atherogenesis. Some authors consider sleep apnea to be an acute risk factor for the rupture of vulnerable plaques, resulting in acute myocardial infarction. ${ }^{9}$ The increased incidence of myocardial ischemia has been reported among patients with coronary heart disease and OSA, ${ }^{4,6}$ and changes in the ST-segment have also been observed during sleep in OSA patients and in those without coronary obstructions. ${ }^{10}$ Moreover, increased sympathetic activity may trigger malignant ventricular arrhythmias and sudden death. ${ }^{11}$ Nocturnal ventricular arrhythmias were observed in patients with severe apnea, ${ }^{12}$ but others have reported only isolated ventricular ectopic beats. ${ }^{13}$

These observations cumulatively suggest an association between OSA and cardiovascular disease; however, the relationship between sleep apnea and ischemic events remains controversial.

The present study was designed to assess the possible influence of the degree of OSA on myocardial ischemia, heart rate variability and arrhythmias in patients with stable coronary heart disease. Our goal was to elucidate the relationship between sleep apnea and ischemic events.

\section{MATERIALS AND METHODS}

This study involved outpatients with stable ischemic heart disease at a Tertiary Cardiovascular Care Center at Hospital das Clínicas, Faculdade de Medicina, Univerisdade de São Paulo. Patients were recruited to participate in the study from July 2002 to June 2005 and all gave their written informed consent. The study was approved by the Hospital Ethical Committee. Individuals initially completed the Berlin Questionnaire $^{14}$ in order to assess the clinical probability of having OSA. We only included patients at high risk for sleep apnea. Exclusion criteria included persistent electrocardiographic changes that would compromise the diagnosis of ischemia (bundle-branch block, high-degree atrioventricular block, atrial fibrillation or marked left ventricular hypertrophy), congestive heart failure, severe ventricular dysfunction, recent (less than 6 months prior) acute myocardial infarction, unstable angina, myocardial revascularization, stroke, artificial cardiac pacemaker and dependence on medications such as digoxin, diuretics, coronary vasodilators, beta-blockers or anti-arrhythmic drugs.

We enrolled a total of 53 patients with documented ischemic heart disease, $40(75.5 \%)$ of whom were men with ages ranging from 31 to 80 yrs (mean 58.8 yrs). Forty-one (77.4\%) patients were submitted to coronary arteriography 1-3 months before recruitment. Twenty-seven (50.94\%) patients had angina or previous myocardial infarction and the remaining patients exhibited positive exercise stress test results or myocardial perfusion scintigraphy. A significant coronary lesion was defined by a $70 \%$ or greater reduction in luminal diameter in a major coronary artery or in a major branch. A $50 \%$ or greater stenosis in the left main coronary artery was also considered significant. ${ }^{15}$ The left ventricular ejection fraction was calculated using the modified Dodge area-length method. ${ }^{16,17}$ Thirty-two (78\%) patients had multivessel disease, and all patients had an ejection fraction $>40 \%$.

Study protocol: All 53 patients were submitted to simultaneous 24-hour ambulatory electrocardiographic monitoring (Holter system) and polysomnography in order to analyze myocardial ischemia, heart rate variability and arrhythmias during wakefulness and sleep. Drugs that could interfere with ECG analysis (e.g., beta blockers, calcium antagonists, long-acting nitrates and digitalis) were withheld for 3 to 7 days before initiation of the protocol. During this period, patients were instructed to take sublingual nitrates as needed for symptoms and to contact the main investigator immediately if disabling symptoms occurred.

Polysomnography was performed in the Sleep Laboratory using an Embla system with digital recording capability (Embla, Flagra hf Medical Devices, Reykjavik, Iceland). Physiological sensor leads were placed on the patients in order to record brain electrical activity, eye and jaw muscle movement, leg muscle movement, airflow, respiratory effort (chest and abdominal excursions), electrocardiogram and oxygen saturation. Apnea was defined as a complete cessation of airflow for at least 10 seconds, and hypopnea was defined as a reduction in respiratory signals for at least 10 seconds associated with an oxygen desaturation of $3 \% .^{3,18}$ The apnea-hypopnea index (AHI) was calculated in terms of the number of apneas/hypopneas per hour of sleep (3). OSA was diagnosed in subjects with an $\mathrm{AHI} \geq 5$. $^{2,19}$

Patients were divided into two groups according to their AHI, a Control group ( $\mathrm{AHI} \leq 15)$ consisting of 23 patients and an Apnea group (AHI>15) consisting of 30 patients. In the Apnea group, a subgroup of 13 patients with severe apnea (AHI>30) was analyzed separately (Severe Apnea group) and compared to the Control group.

Ambulatory electrocardiograph monitoring using the 
Holter system was conducted for 24 consecutive hours and obtained by a portable two-channel analog recorder (Marquette series 8500) with a fixed calibration of $1 \mathrm{mV}=$ $10 \mathrm{~mm}$ and wave recording in modulated amplitude (MA) mode. Two bipolar leads, the CM5 (exploring electrode in the V5 position) and the CM1 or modified D2 (exploring electrode in an inferior lead), were used. To acquire the neutral value, an electrode was placed close to the final costal arches, next to the midclavicular line. Baseline electrocardiograms were recorded in all patients. After the monitor was withdrawn, the tapes were analyzed using the MARS system (Marquette). Maximum, minimum and mean heart rates were determined and the occurrence of ST-segment deviations and arrhythmias were recorded. An ischemic episode was defined as either a transient ST-segment elevation or a horizontal or downsloping STsegment depression of $1 \mathrm{~mm}$ or more from the baseline, measured 60 to $80 \mathrm{~ms}$ after the $\mathrm{J}$ point and lasting 1 minute or longer. ${ }^{15,20}$ The heart rate variability was determined by time- and frequency-domain analysis ${ }^{20,21}$ and quantified every 5 minutes over a total period of 30 minutes. For each patient, two values of heart rate variability were obtained immediately before deploying the polysomnography hardware (pre-polysomnography period) and immediately after removing it (post-polysomnography period). The time-domain parameters included standard deviations of all $R-R$ intervals, the percentage of differences between $R-R$ intervals that differed more than $50 \mathrm{~ms}$ and the root mean square of the difference between two adjacent R-R intervals
(SDNN, pNN50 and RMSSD, respectively). The frequencydomain components included the low-frequency (LF) component (between 0.04-0.15 Hz) and the high frequency (HF) component (between 0.15-0.40 Hz). From these values, the ratio of LF/HF was also determined. Arrhythmias were analyzed manually if diagnosed, and sinus pauses $\geq 3$ seconds were considered significant.

Patients received a questionnaire and were instructed to report their activities and the occurrence of any adverse symptoms.

Statistical analysis: Results are expressed as mean \pm SD. The chi-square test or Fisher's exact test (for any expected frequencies of less than five) were used for the analysis of categorical variables. A Student's t-test was used for continuous variables. A non-parametric Mann-Whitney test was used when groups were assumed to have an unequal distribution. To compare wakefulness and sleep, a nonparametric Wilcoxon test was used because the assumed normality of the data was rejected. The statistical software used was SAS 9.1. The significance level used for the tests was set to $5 \%$.

\section{RESULTS}

Baseline clinical characteristics are listed in table 1. No significant differences were observed among the groups except for the higher blood pressure levels in the Severe Apnea group and the higher diastolic blood pressure in the Apnea group when compared to the Control group. The

Table 1 - Baseline clinical characteristics

\begin{tabular}{|c|c|c|c|}
\hline & Control (AHI $\leq 15 ; \mathrm{n}=23)$ & Apnea $($ AHI $>15 ; n=30)$ & Severe Apnea $(\mathrm{AHI}>30 ; \mathrm{n}=13)$ \\
\hline Age (years) & $57.47 \pm 10.59$ & $59.00 \pm 10.42$ & $58.38 \pm 10.17$ \\
\hline Females (\%) & 34.78 & 16.67 & 30.77 \\
\hline BMI $\left(\mathrm{kg} / \mathrm{m}^{2}\right)$ & $27.94 \pm 3.95$ & $29.90 \pm 7.85$ & $32.76 \pm 10.73$ \\
\hline $\mathrm{SBP}(\mathrm{mmHg})$ & $136.08 \pm 16.71$ & $146.33 \pm 23.03$ & $158.46 \pm 23.75 * *$ \\
\hline DBP (mmHg) & $81.30 \pm 12.17$ & $91.33 \pm 16.96^{*}$ & $96.15 \pm 19.80 * *$ \\
\hline Symptoms (\%) & 52.17 & 50.00 & 53.85 \\
\hline Hypertension (\%) & 65.22 & 83.33 & 92.31 \\
\hline Diabetes (\%) & 13.04 & 36.67 & 23.08 \\
\hline Dyslipidemia (\%) & 39.13 & 40.00 & 38.46 \\
\hline Smokers (\%) & 21.74 & 10.00 & 15.38 \\
\hline Snoring $(\%)$ & 85.71 & 88.46 & 100 \\
\hline Neck $(\mathrm{cm})$ & $37.13 \pm 8.10$ & $39.63 \pm 3.51$ & $40.57 \pm 4.07$ \\
\hline SpO2 - awake (\%) & $94.03 \pm 1.70$ & $93.32 \pm 1.72$ & $93.08 \pm 2.02$ \\
\hline SpO2max - sleep $(\%)$ & $93.30 \pm 1.98$ & $92.27 \pm 2.43$ & $91.56 \pm 3.04$ \\
\hline SpO2min - sleep (\%) & $85.65 \pm 2.99$ & $76.20 \pm 9.40^{*}$ & $76.30 \pm 7.66^{* *}$ \\
\hline
\end{tabular}

*Apnea vs. Control $\mathrm{p}<0.05$; ** Severe Apnea vs. Control $\mathrm{p}<0.05$

BMI: body mass index; SBP: systolic blood pressure; DBP: diastolic blood pressure; $\mathrm{SpO}_{2}$ : oxygen saturation 
oxygen saturation levels did not differ when the subjects were awake. There was, however, a significant decrease in minimum oxygen saturation during sleep in the Apnea and Severe Apnea groups when compared to the Control group. The groups did not differ in the extent of coronary disease or ventricular impairment. Multivessel coronary disease was detected in $76.5 \%, 79.2 \%$ and $81.8 \%$ of the Control, Apnea and Severe Apnea patients, respectively.

All patients remained clinically stable during the study and no patient awoke due to nocturnal angina.

Ischemic episodes were quantified in terms of number and duration. Myocardial ischemia was recorded in 39 (73.6\%) patients, 19 of whom (35.8\%) also presented with ischemia during sleep. The number and duration of ischemic episodes per hour decreased significantly in all groups during sleep as compared to wakefulness (Figure 1).

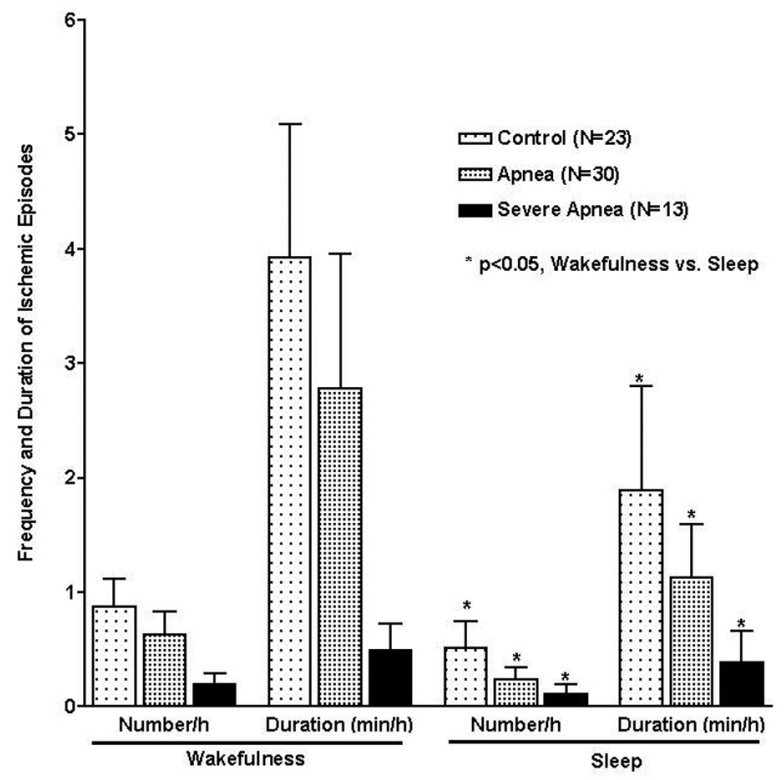

Figure 1 - Comparison of the number and duration of ischemic episodes per hour during wakefulness and sleep in the same group

There was no significant difference in the number or duration of ischemic episodes during sleep among the groups (Figure 2). During wakefulness, however, there were significantly fewer and shorter ischemic episodes in the Severe Apnea group as compared to the Control group.

Heart rate variability was not significantly different between the three groups during the pre- and postpolysomnography periods (Table 2). When comparing the post-polysomnography period to the pre-polysomnography period in the Control group, we found a decrease in the time domain parameters. This difference, however, was only significant for SDNN values $(\mathrm{p}=0.014)$. An increase in the LF component and a decrease in the HF component were also observed, but the differences were not significant.

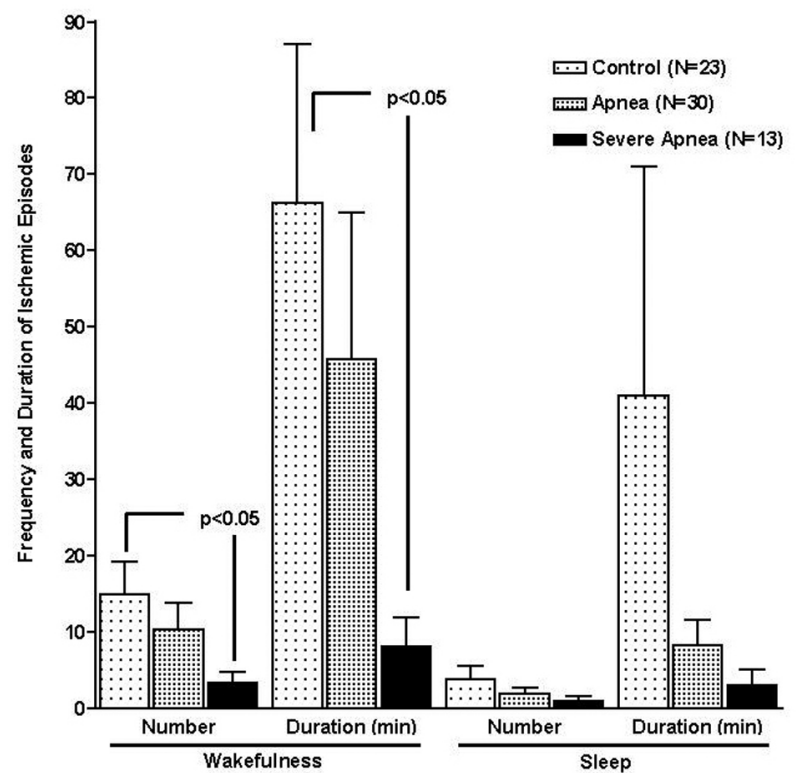

Figure 2 - Comparison of the number and duration of ischemic episodes in the different groups

Table 2 - Heart rate variability in the three groups during pre- and postpolysomnography periods

\begin{tabular}{llcc}
\hline HRV & & $\begin{array}{c}\text { Pre-P } \\
\text { Mean } \pm \text { SD }\end{array}$ & $\begin{array}{c}\text { Post-P } \\
\text { Mean } \pm \text { SD }\end{array}$ \\
\hline $\begin{array}{l}\text { Control } \\
(\mathrm{n}=23)\end{array}$ & SDNN $(\mathrm{ms})$ & $78.56 \pm 26.57$ & $64.39 \pm 21.40$ \\
& RMSSD (ms) & $35.00 \pm 28.75$ & $29.27 \pm 15.26$ \\
& PNN50 (ms) & $12.04 \pm 16.76$ & $8.78 \pm 11.43$ \\
& LF (ms) & $702.21 \pm 410.78$ & $791.17 \pm 525.98$ \\
& HF (ms) & $312.43 \pm 402.05$ & $247.56 \pm 300.49$ \\
& LF/HF & $4.08 \pm 3.77$ & $6.26 \pm 8.98$ \\
\hline Apnea & SDNN (ms) & $73.06 \pm 31.83$ & $61.56 \pm 25.69$ \\
$(\mathrm{n}=30)$ & RMSSD (ms) & $28.20 \pm 10.90$ & $29.83 \pm 21.30$ \\
& PNN50 (ms) & $7.86 \pm 7.59$ & $9.30 \pm 15.40$ \\
& LF (ms) & $717.76 \pm 563.65$ & $661.20 \pm 720.62$ \\
& HF (ms) & $182.50 \pm 146.00$ & $222.76 \pm 373.14$ \\
& LF/HF & $4.20 \pm 3.05$ & $5.13 \pm 3.83$ \\
\hline Severe Apnea & SDNN (ms) & $68.46 \pm 25.19$ & $55.84 \pm 24.95$ \\
$(\mathrm{n}=13)$ & RMSSD (ms) & $28.53 \pm 10.05$ & $32.07 \pm 26.06$ \\
& PNN50 (ms) & $8.00 \pm 6.28$ & $10.15 \pm 18.08$ \\
& LF (ms) & $632.23 \pm 513.72$ & $534.84 \pm 493.63$ \\
& HF (ms) & $209.00 \pm 183.06$ & $260.92 \pm 492.62$ \\
& LF/HF & $3.38 \pm 2.53$ & $5.07 \pm 3.68$ \\
\hline
\end{tabular}

Pre-P: pre-polysomnography; Post-P: post-polysomnography; HRV: heart rate variability; $\mathrm{LF}=$ low frequency; $\mathrm{HF}=$ high frequency

In the Apnea and Severe Apnea groups, a non-uniform decrease in SDNN and an increase in RMSSD and PNN50 were observed, but only the decreases in SDNN values in the 
Apnea group were significant $(\mathrm{p}=0.041)$. We also observed a decrease in LF and an increase HF in both the Apnea and Severe Apnea groups, but these differences were not significant. The LF/HF ratio increased in all groups, but the changes were not significant.

We did not observe sinus pauses $\geq 3$ seconds, atrial fibrillation, flutter or any type of conduction defect or malignant ventricular arrhythmias (ventricular tachycardia or ventricular fibrillation). Patients in all groups, with few exceptions, presented with fewer than 10 ectopic beats per hour during monitoring. Forty-five $(84.9 \%)$ patients exhibited at least one supraventricular ectopic beat while awake and $43(81.1 \%)$ patients had one while asleep. Isolated ventricular ectopic beats or pairs were detected in 42 patients (79.2\%) during wakefulness and in 37 patients (69.8\%) during sleep. Patients in the Apnea and Severe Apnea groups presented with a decrease in the number of arrhythmias per hour during sleep as compared to wakefulness, except for the supraventricular ectopic beats observed in the Apnea group. These differences, however, were not significant. Supraventricular ectopic beats in the Control group predominated during sleep (Figure 3). No differences were observed among the groups with respect to the occurrence of ventricular or supraventricular arrhythmias.

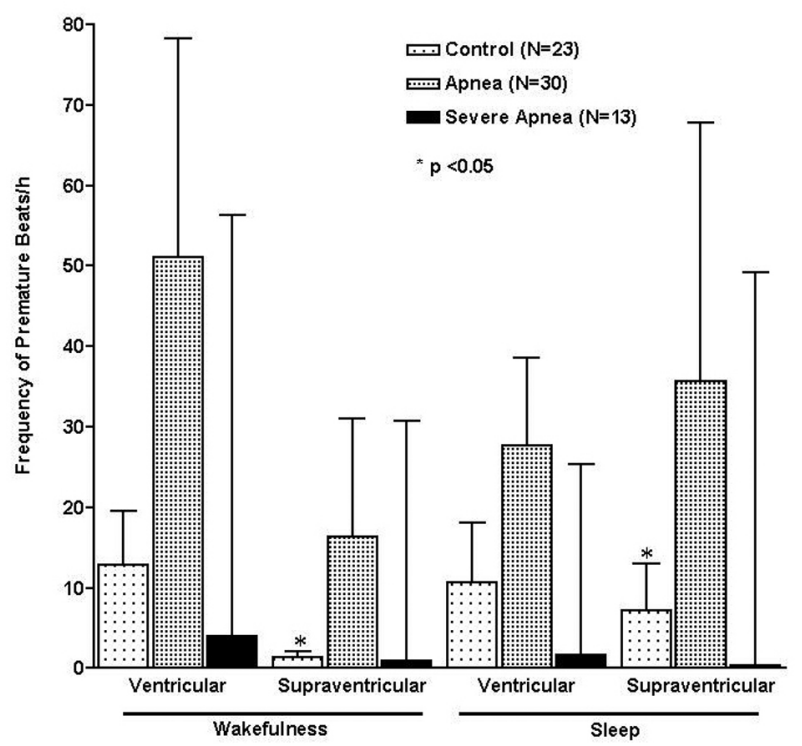

Figure 3 - Comparison of the number of ectopic ventricular and supraventricular beats per hour during wakefulness and sleep in the same group

\section{DISCUSSION}

In the present study, we were unable to demonstrate a relationship between OSA and the occurrence of ischemia, arrhythmias or heart rate variability in a select group of patients with coronary disease. These findings were unexpected, as hypoxemia in sleep apnea is associated with a risk of cardiac events, especially in patients with severe apnea. Gastaut et al. ${ }^{22}$ described a patient with Pickwickian syndrome and suggested that the majority of individuals suffering from this syndrome become drowsy during the day and sleep poorly at night because of a primary disturbance in wakefulness-sleep regulation due to their obesity. Since this report, many observations have been published regarding patients with sleep disturbances due to reduction or cessation of breathing for short periods. ${ }^{23}$ Today, OSA is considered to be a risk factor for cardiovascular events and sudden cardiac death..$^{24,25}$ Its association with systemic high blood pressure has been suggested by a series of studies. Whether there is a relationship between nocturnal OSA and ischemia, however, remains controversial. ${ }^{26}$

Ambulatory electrocardiographic monitoring in patients with stable ischemic heart disease has demonstrated a circadian pattern of ischemia, finding that most ischemic episodes occur during the early morning hours. ${ }^{27}$ In the present study, the circadian pattern of ischemia did not change, which led us to conclude that OSA most likely did not influence the occurrence of ischemic episodes in our patients. The comparison between sleep and wakefulness showed a significant decrease in the number and duration of ischemic episodes during sleep in the three groups, as is commonly found in patients suffering from coronary disease without OSA. Although we cannot definitively explain this finding, we can assume that the ischemia was primarily associated with effort during daily activities and that hypoxia during sleep apnea was insufficiently severe to increase ischemic episodes. If this is the case, the most likely reasons why patients in the Severe Apnea group exhibited less ischemia during wakefulness compared to the Control group is because they commonly become drowsy during the day and have a higher body mass index. These may be limiting factors for physical exercise and most likely result in fewer effort-related ischemic episodes. Furthermore, the occurrence of ischemic episodes in the Apnea or Severe Apnea groups did not differ during sleep compared to the Control group. The incidence of coronary artery disease and ventricular impairment was similar in all groups and did not influence our results.

Previous studies have reported different conclusions from ours. Schäfer et al. ${ }^{28}$ analyzed 14 patients with OSA and coronary disease. They found that $85 \%$ of the ischemic episodes were concomitant with apneas and that nitrate administration failed to reduce the likelihood of ischemic episodes. These results differ from ours in many respects. The number of patients in their study was smaller, they employed conventional electrocardiograms instead of Holter monitoring and they defined an ischemic episode as when 
the ST-segment deviation lasted 10 seconds or longer. This definition of ischemia is not consistent with the general consensus and it is possible that many ST-segment deviations thus did not reflect true ischemia. This may explain why nitrates failed to relieve the considered ischemic episodes. Peled et al. ${ }^{29}$ also studied 51 patients with OSA and coronary disease using inclusion criteria and methods similar to ours. They observed an exacerbation of ischemic events during sleep and amelioration with continuous positive airway pressure. Furthermore, the AHI did not differentiate between patients with and without nocturnal ischemia, a result similar to ours. Conversely, Mooe et al. ${ }^{30}$ reported an observational study that also used polysomnography and Holter monitoring in 132 patients who had been referred for coronary angiography on account of disabling angina. They observed a relationship between apnea/desaturation and ST-segment deviations when the ST-segment deviation occurred within 2 minutes after the breathing event. Nocturnal ischemic episodes occurred in $31 \%$ patients, but the association with apnea/desaturation was found in only $19 \%$ of the patients, suggesting only a limited correlation between ischemic episodes and sleep-disordered breathing. ${ }^{30}$ Although their methods and definition of ischemia were similar to ours, their patients were randomly selected from a group that had been referred for coronary angiography and that did not necessarily exhibit any symptoms of OSA. STsegment depressions during sleep were described in patients with OSA and without coronary disease. ${ }^{10}$

In the present study, heart rate variability was not studied during sleep since it is influenced by respiration, and the respiratory events of sleep apnea may compromise the primary objective of associating heart rate variability with autonomic changes in these patients. The comparative analysis of heart rate variability in the three groups did not reveal significant differences. In the Control group, changes in heart rate variability occurred as expected. We also observed an increase in LF and the LF/HF ratio in the post-polysomnography period, reflecting sympathetic predominance after awakening. In the Apnea and Severe Apnea groups, however, there were increases in certain parameters associated with vagal tone (i.e., RMSSD, PNN50 and HF), suggesting that these patients did not have a physiological sleep period and did not really "wake up". Our results and those of others ${ }^{31-34}$ suggest that patients with severe sleep apnea may not exhibit marked differences between sleep and wakefulness and, as a result, a nonhomogeneous variability in heart rate will likely occur. The relationship between OSA and changes in autonomic activity is still controversial and deserves further investigation.

Arrhythmias were infrequent in our cohort. We did not observe any serious arrhythmias such as atrial fibrillation, bouts of ventricular tachycardia, severe bradyarrhythmias or conduction defects, and no differences were detected among the three groups in respect of the occurrence of ectopic beats. There was a non-significant decrease in ventricular and supraventricular ectopic beats during sleep when compared to wakefulness in all groups except for the Control group, where an increase in supraventricular ectopic beats was observed during sleep. Past studies have associated sleep respiratory disturbances with atrial fibrillation but only in patients with congestive heart failure or recent myocardial revascularization, ${ }^{35,36}$ which were exclusion criteria in our study. Recently, Olmetti et al. ${ }^{37}$ suggested that nocturnal bradyarrhythmias are associated with severe OSA. However, Clementy et al. ${ }^{38}$ concluded that although bradycardias may dominate in these patients, it is difficult to link arrhythmias to sleep apnea syndrome or to an associated disease in the absence of controlled studies.

The controversies regarding the relationships between sleep apnea and myocardial ischemia, and between heart rate variability and arrhythmias can be explained in part by selection bias and also because OSA is a complex syndrome that involves hypoxemia, endothelial dysfunction, inflammation and sympathetic stimulation. ${ }^{7-9}$

We conclude that in our selected group of patients with stable coronary disease, the severity of OSA was not directly associated with myocardial ischemia, heart rate variability or arrhythmias. Furthermore, OSA did not change the circadian pattern of ischemia. Our study was limited to a selected group of patients with stable coronary disease and without signs and symptoms of heart failure. Our results may therefore not be applicable to patients with severe angina or ventricular dysfunction.

\section{ACKNOWLEDGEMENT}

We thank Dr. Desiderio Favarato for important contributions to the manuscript and Creusa Dal Bó for assistance with the statistical analyses.

\section{REFERENCES}

1. Young T, Palta M, Dempsey J, Skatrud J, Weber S, Badr S. The occurrence of sleep-disordered breathing among middle-aged adults. N Engl J Méd. 1993;328:1230-5.
2. Nery LE, Moura SMT, Bittencourt LRA, Bagnato MC, Gregório LC, Tufik S. Síndrome da Apnéia do Sono Obstrutiva. In: Cukier A, Nakatani J, Morrone N. ed. Pneumologia - Atualização e Reciclagem. São Paulo: Atheneu. 1998:104-11. 
3. Drager LF, Bortolotto LA, Lorenzi MC, Figueiredo AC, Krieger EM, Lorenzi-Filho G. Early signs of atherosclerosis in obstructive sleep apnea. Am J Respir Crit Care Med. 2005;175:613-8

4. Shahar E, Whitney CW, Redline S, Lee ET, Newman AB, Javier Nieto $\mathrm{F}$, et al. Sleep-disordered breathing and cardiovascular disease: crosssectional results of the Sleep Heart Health Study. Am J Respir Crit Care Med. 2001;163:19-25.

5. Naughton MT, Bradley TD. Sleep apnea in congestive heart failure. Clin Chest Med. 1998;19:99-113.

6. Peker Y, Kraiczi H, Hedner J, Loth S, Johansson A, Bende M. An independent association between obstructive sleep apnoea and coronary artery disease. Eur Respir J. 1999;14:179-84.

7. Somers VK, Dyken ME, Clary MP, Abboud FM. Sympathetic neural mechanisms in obstructive sleep apnea. J Clin Invest. 1995;96:1897904.

8. Kato M, Roberts-Thomson P, Phillips BG, Haynes WG, Winnicki M, Accurso V, et al. Impairment of endothelium-dependent vasodilation of resistance vessels in patients with obstructive sleep apnea. Circulation. 2000;102:2607-10.

9. Shamsuzzaman AS, Winnicki M, Lanfranchi P, Wolk R, Kara T, Accurso $\mathrm{V}$, et al. Elevated C-reactive protein in patients with obstructive sleep apnea. Circulation. 2002;105:2462-4.

10. Hanly P, Sasson Z, Zuberi N, Lunn K . ST-segment depression during sleep in obstructive sleep apnea. Am J Cardiol. 1993;71:1341-5.

11. Schwartz PJ, La Rovere MT, Vanoli E. Autonomic nervous system and sudden cardiac death. Experimental basis and clinical observations for post-myocardial infarction risk stratification. Circulation. 1992;85(Suppl):I-77- I-91.

12. Lazarus A, Py A, Guerin F, Valty J, Le Heuzey JY. Arrhythmia and syndrome of obstructive sleep apnea in adults. Arch Mal Coeur Vaiss. 1993;86:1753-9.

13. Guilleminault C, Connolly SJ, Winkle RA. Cardiac arrhythmia and conduction disturbances during sleep in 400 patients with sleep apnea syndrome. Am J Cardiol. 1983;52:490-4.

14. Netzer NC, Stoohs RA, Netzer CM, Clark K, Strohl KP. Using the Berlin Questionnaire to identify patients at risk for the sleep apnea syndrome. Ann Intern Méd. 1999;131:485-91.

15. Solimene MC, Ramires JA, Gruppi CJ, Alfieri RG, de Oliveira SF, Da Luz PL, et al. Prognostic significance of silent myocardial ischemia after a first uncomplicated myocardial infarction. Int J Cardiol. 1993;38:417.

16. Dodge HT, Sandler H, Ballew DW, Lord JD Jr. The use of biplane angiocardigraphy for the measurement of left ventricular volume in man. Am Heart J. 1960;60:762-6.

17. Kennedy JW, Trenholme SE, Kasser IS. Left ventricular volume and mass from single-plane cineangiocardiogram. A comparison of anteroposterior and right anterior oblique methods. Am Heart J. 1970;80:343-52

18. Alonso-Fernandez A, Garcia-Rio F, Racionero MA, Pino JM, Ortuño F, Martinez I, et al. Cardiac rhythm disturbances and ST-segment depression episodes in patients with obstructive sleep apnea-hypopnea syndrome and its mechanisms. Chest. 2005; 127: 15-22.
19. Sleep-related breathing disorders in adults: recommendations for syndrome definition and measurement techniques in clinical research. The Report of an American Academy of Sleep Medicine Task Force. Sleep. 1999;22:667-89.

20. Crawford MH, Bernstein SJ, Deedwania PC, Di Marco JP, Ferrick $\mathrm{KJ}$, Garson A Jr, et al. ACC/AHA Guidelines for Ambulatory Electrocardiography. A report ot the American College of Cardiology/ American Heart association Task Force on Practice Guidelines (Committee to Revise the Guidelines for Ambulatory Electrocardiography). Developed in collaboration with the North American Society for Pacing and Electrophysiology. J Am Coll Cardiol. 1999;34:912-48.

21. Heart rate variability: standards of measurement, physiological interpretation and clinical use. Task Force of the European Society of Cardiology and the North American Society of Pacing and Electrophysiology. Circulation. 1996;93:1043-65.

22. Gastaut H, Tassinari CA, Duron B. Polygraphic study of the episodic diurnal and nocturnal (hypnic and respiratory) manifestations of the Pickwick syndrome. Brain Res. 1966;1:167-86.

23. Peters RW. Obstructive sleep apnea and cardiovascular disease. Chest. $2005 ; 127: 1-3$

24. Gami SA, Howard DE, Olson EJ, Somers VK. Day-night pattern of sudden death in obstructive sleep apnea. N Engl J Med. 2005;352:120614.

25. Yaggi HK, Concato J, Kernan WN, Lichtman JH, Brass LM, Mohsenin V. Obstructive sleep apnea as a risk factor for stroke and death. N Engl J Med. 2005;353:2034-41.

26. Lattimore JL; Celermajer DS, Wilcox I. Obstructive sleep apnea and cardiovascular disease. J Am Coll Cardiol. 2003;41:1429-37.

27. Hausamann D, Nikkutta P, Trappe HJ, Daniel WG, Wenzlaff P, Lichtlen PR. Circadian distribution of characteristics of ischemic episodes in patients with stable coronary artery disease. Am J Cardiol. 1990;66:66872.

28. Schäfer H, Koehler U, Ploch T, Peter JH. Sleep-related myocardial ischemia and sleep structure in patients with obstructive sleep apnea and coronary heart disease. Chest. 1997;111:387-93.

29. Peled N, Abinader EG, Pillar G, Sharif D, Lavie P. Nocturnal ischemic events in patients with obstructive sleep apnea syndrome and ischemic heart disease. Effects of continuous positive air pressure treatment. J Am Coll Cardiol. 1999;34:1744-9.

30. Mooe T, Franklin KA, Wiklund U, Rabben T, Holmström K. Sleepdisordered breathing and myocardial ischemia in patients with coronary disease. Chest. 2000; 117: 1597-602.

31. Bauer T, Ewig S, Schafer H, Jelen E, Omran H, Luderitz B. Heart rate variability in patients with sleep-related breathing disorders. Cardiology. 1996;87:492-6.

32. Gula LJ, Krahn AD, Skanes A, Ferguson KA, George C, Yee R. Heart rate variability in sleep apnea: a prospective study and frequency domain analysis. Ann Noninvasive Electrocardiol. 2003;8:144-9.

33. Marin JM, Carrizo SJ, Vicente E, Agusti AGN. Long-term cardiovascular outcomes in men with obstructive sleep apnoea-hypopnoea with and without treatment with continuous positive airway pressure: an observational study. Lancet. 2005;365:1046-53. 
34. Reynolds EB, Seda G, Ware JC, Vinik AI, Risk MR, Fishback NF. Autonomic function in sleep apnea patients: increased heart rate variability except during REM sleep in obese patients. Sleep Breath. 2007;11:53-60.

35. Mooe T, Gullsby S, Rabben T, Eriksson P. Sleep-disordered breathing: a novel predictor of atrial fibrillation after coronary artery bypass surgery. Coron Artery Dis. 1996;7:475-8.

36. Kanagala R, Murali NS, Friedman PA, Ammash NM, Gersh BJ, Ballman $\mathrm{KV}$, et al. Obstructive Sleep Apnea and recurrence of atrial fibrillation. Circulation. 2003;107:2589-94.
37. Olmetti F, La Rovere MT, Robbi E, Taurino AE, Fanfulla F. Nocturnal cardiac arrhythmia in patients with obstructive sleep apnea. Sleep Med 2008,9:475-80.

38. Clementy J, Bordachar P, Reuter S, Deplagne A, Bordier P. Arrhythmias in sleep apnea syndrome. Presse Med. 2007;36:1012-5. 